Int. J. Electrochem. Sci., 12 (2017) 2485 - 2494

\title{
Electrodeposition of Pt-Ru Alloy Electrocatalysts for Direct Methanol Fuel Cell
}

\author{
Chao $\mathrm{Li}^{l}$, Ruihui Dai ${ }^{2}$, Ruifang $Q i^{2}$, Xiaojia $\mathrm{Wu}^{3}$ and Jingjun $\mathrm{Ma}^{3, *}$ \\ ${ }^{1}$ College of Sciences, Agricultural University of Hebei, Baoding 071001, P.R. China \\ ${ }^{2}$ Department of Basic Courses, Agricultural University of Hebei, Huanghua 061100, P.R. China \\ ${ }^{3}$ College of Science and Technology, Agricultural University of Hebei, Huanghua 061100, P.R. China \\ *E-mail: jingjunma_hebeiag@foxmail.com
}

doi: $10.20964 / 2017.03 .13$

Received: 26 November 2016 / Accepted: 5 January 2017 / Published: 12 February 2017

\begin{abstract}
The electrocatalyst based on Pt-Ru alloy was successfully prepared on the carbon paper through electrodeposition approach. The deposition potential and time was tuned to control the particle size and density. Brunauer-Emmett-Teller (BET) isotherms, scanning electron microscopy (SEM), X-ray diffraction (XRD) and X-ray photoelectron spectroscopy were used to characterize the catalyst particles. The highest catalytic activity was observed with the Pt-Ru electrocatalyst towards the oxidation of methanol, Besides, the Pt-Ru electrocatalyst also exhibited the most tolerance against the poisoning of $\mathrm{CO}$.
\end{abstract}

Keywords: Electrocatalyst; Pt-Ru alloy; Electrodeposition; Methanol fuel cell; Carbon monoxide poisoning

\section{FULL TEXT}

(C) 2017 The Authors. Published by ESG (www.electrochemsci.org). This article is an open access article distributed under the terms and conditions of the Creative Commons Attribution license (http://creativecommons.org/licenses/by/4.0/). 